Final Author Version

Prepared for J. Phys. Chem. A

June 28, 2006

\title{
Optimizing the Performance of the Multiconfiguration
}

\section{Molecular Mechanics Method}

\author{
Oksana Tishchenko and Donald G. Truhlar* \\ Chemistry Department and Supercomputing Institute, University of Minnesota, \\ Minneapolis, MN 55455-0431
}

Received: June 292006

Accepted: September 202006

\begin{abstract}
Multiconfiguration molecular mechanics (MCMM) is a general algorithm for constructing potential energy surfaces for reactive systems (Kim, Y.; Corchado, J. C.; Villà, J.; Xing, J. and Truhlar, D. G. J. Chem. Phys. 2000, 112, 2718). This paper illustrates how the performance of the MCMM method can be improved by adopting improved molecular mechanics parameters. We carry out calculations of reaction rate constants using variational transition state theory with optimized multidimensional tunneling on the MCMM PESs for three hydrogen transfer reactions, and we compare the results to direct dynamics. We find that the MCMM method with as little as one electronic structure Hessian can describe the dynamically important regions of the ground-electronic state PES, including the corner-cutting-tunneling region of the reaction swath, with practical accuracy.
\end{abstract}

\footnotetext{
*Corresponding Author. Email: truhlar@umn.edu
} 


\section{Introduction}

Multiconfiguration molecular mechanics ${ }^{1}$ (MCMM) has been developed as a systematic scheme to generate potential energy surfaces for chemical reactions by fitting high-level electronic structure data by taking advantage of previously available nonreactive molecular mechanics ${ }^{2-5}$ potentials to build in a zero-order description of the nonreactive modes. In this way, MCMM extends molecular mechanics ${ }^{2-5}(\mathrm{MM})$ to reactive systems. In the MCMM method, the Born-Oppenheimer potential energy at a geometry $\mathbf{q}$ is represented as the lowest eigenvalue of the $2 \times 2$ electronically diabatic Hamiltonian matrix:

$$
\mathbf{V}(\mathbf{q})=\left(\begin{array}{ll}
V_{11}(\mathbf{q}) & V_{12}(\mathbf{q}) \\
V_{12}(\mathbf{q}) & V_{22}(\mathbf{q})
\end{array}\right)
$$

where, following Warshel and Weiss, ${ }^{6}$ the diagonal elements are analytic MM PESs for reactants and products. The diagonal elements may be interpreted as the energies of individual valence bond configurations, as in semiempirical valence bond theory, ${ }^{7-23}$ and therefore the off-diagonal element (diabatic coupling) may be interpreted as a resonance integral. The resonance integral and its Taylor's series expansion ${ }^{24,25}$ at a geometry q, are obtained from electronic structure calculations of the Born-Oppenheimer potential energy, and in MCMM these Taylor's series have been joined into a global potential energy surface (PES) by means of multidimensional Shepard interpolation ${ }^{27,} 28$ in internal coordinates. ${ }^{1}$ (An alternative recently proposed is to fit $V_{12}$ by a polynomial times a spherical Gaussian. ${ }^{26}$ ) Implementation of nuclear permutation symmetry into the MCMM algorithm will be described elsewhere. ${ }^{29}$

The MCMM procedure has been tested by rate constant calculations for several hydrogen transfer reactions. ${ }^{1,30}$ A partial electronic-structure-Hessian scheme ${ }^{31}$ has been developed to facilitate the application of the MCMM method to larger systems; it reduces computational effort to generate electronic structure Hessians as input for MCMM. More recently, combined molecular mechanics - quantum mechanics methods 
have been used to generate data at Shepard points. ${ }^{32}$ The present paper reports that refinement of the molecular mechanics parameters considerably improves the efficiency of the MCMM method as compared to the previous ${ }^{1,30,31}$ work. We test the MCMM method with the improved MM parameters for three of the reactions considered in the previous papers, ${ }^{1,30,31}$ in particular:

$$
\begin{gathered}
\mathrm{Cl}+\mathrm{HBr} \rightarrow \mathrm{Br}+\mathrm{HCl} \\
\mathrm{OH}+\mathrm{CH}_{4} \rightarrow \mathrm{CH}_{3}+\mathrm{H}_{2} \mathrm{O}
\end{gathered}
$$

and

$$
\mathrm{NH}_{2}+\mathrm{CH}_{4} \rightarrow \mathrm{CH}_{3}+\mathrm{NH}_{3}
$$

\section{Molecular mechanics}

In the present work, we use the MM3 force field ${ }^{33-36}$ augmented with a few new parameters $^{30}$ (for functionalities that are not present in MM3) and with a modified van der Waals energy term. In the original MM3 force field, the van der Waals interaction energy between two atoms is represented by the Exp-6 potential:

$$
V_{\operatorname{Exp}-6}(r)=\epsilon\left[A e^{-B r / r_{o}}-C\left(\frac{r_{o}}{r}\right)^{6}\right]
$$

where $r_{o}$ is the sum of the van der Waals radii, and $\epsilon$ is an energy parameter. The van der Waals term in the MC-TINKER program that has been used for MCMM calculations ${ }^{1,30-32}$ is written as a linear combination of (1) and an $r^{-12}$ repulsive term:

$$
V_{v d w}(r)=\epsilon\left[A e^{-B r / r_{o}}-C\left(\frac{r_{o}}{r}\right)^{6}\right]+D E\left(\frac{r_{o}}{r}\right)^{12}
$$

where $E$ is defined as

$$
E=\left.\frac{V_{6-E x p}(r)}{\left(\frac{r_{o}}{r}\right)^{12}}\right|_{r=\frac{1}{2} r_{o}} .
$$

The values for $A, B$, and $C$ are the same as in the original MM3 formulation, ${ }^{34}$ viz. $184000.0,12.0$, and 2.25, respectively. In MM3, $D$ is zero. However, in our previous 
work (mentioned in the manual of MC-TINKER ${ }^{37}$ but not in the $\operatorname{articles}^{1,30,31}$ ) we set $D=0.2$ to avoid $V_{E x p-6}(r)$ tending to $-\infty$ as $r \rightarrow 0$. In the present work we found that the convergence of the MCMM procedure is more sensitive than we had expected to introducing this change in $V_{\operatorname{Exp}-6}(r)$.

Within MM3, the van der Waals energy between two molecules is computed as a sum of individual interactions for each pair of atoms (excluding 1-2, 1-3, and 1-4 interactions), and the largest component is usually the one that describes the interaction between the atoms that come into closest proximity. In particular, in the hydrogen transfer reactions $\mathrm{Y}+\mathrm{HX} \rightarrow \mathrm{YH}+\mathrm{X}$, the largest components usually correspond to the $\mathrm{Y} \cdots \mathrm{H}$ interaction in the $\mathrm{X}-\mathrm{H} \cdots \mathrm{Y}$ MM term and to the $\mathrm{X} \cdots \mathrm{H}$ interaction in the $\mathrm{X} \cdots \mathrm{H}-\mathrm{Y}$ MM term. In the regions of the PESs close to the saddle point of the reaction, the van der Waals terms often dominate all other MM terms and thus control the magnitudes of the the matrix elements $V_{11}$ and $V_{22}$.

Figure 1 illustrates the magnitudes of the MM terms in the dynamically important region of reaction R3. In the MCMM- $N$ notation used in the figure captions and throughout this paper, $N$ indicates the number of nonstationary points with electronic structure input (energy, gradient, and Hessian) included in the Shepard interpolation. We also use the energy and Hessian at the saddle point, so the total number $N_{H}$ of electronic structure Hessians used is $N+1$. For example, MCMM-0 means that the interpolated surface is constructed using input information at three points, i.e., electronic structure data at the reaction saddle points and MM data at two MM minima; MCMM-1 means that in addition to these three points, one nonstationary point with electronic structure Hessian is added, and so on. Because we also place Shepard points at the reactant and product van der Waals well ( $V_{12}$ and its derivatives are zero at these points), the number of Shepard points is $N+3$. In Figure 1, $V_{v d W}(I)$ and $V_{v d W}(I I)$ denote the van der Waals energies of valence bond configurations I and II that describe 
the reactants and products, respectively; and $V^{\prime}$ denotes all other contributions to the MM energy of configuration (I), resulting from the bond stretching and valence bending terms. Setting $D$ as large as 0.2 , as was done in the previous work, leads to large values of $V_{v d W}$, which, in turn, lead to large values of $V_{11}$ and $V_{22}$. Then, to fit the Born-Oppenheimer potential energy surface, one needs a large value $V_{12}$. Effectively one requires a cancellation between a high value of the diabatic energy and a large energy lowering due to resonance. As one moves away from the point where BornOppenheimer data was used for the fit, this cancellation may be imperfect, and the resulting MCMM fit may deteriorate. In the previous work that resulted in an underestimation of the potential energy on the concave side of the reaction path (cf. Figure 12 of Ref. 30). This is illustrated in Table 1, which lists the MCMM energies along with the corresponding matrix elements at three geometries for reaction R3. With $D=0.2$, even with 11 electronic structure Hessians (MCMM-10, Ref. 30), the PES is inaccurate at geometries far away from the locations of the data points.

It is therefore instructive to monitor the magnitudes of the matrix elements in the dynamically important region. To make the van der Waals function (1) softer at small $r$, we reduced the value of $D$ and set it, in particular, to 0.01 (in fact the results are not overly sensitive to $D$ values of about this magnitude, and $D=0.005-0.01$ seems quite reasonable for a few other reactions we examined as well). A rather convenient way to find a good value for $D$ for a particular reaction is to choose the one that minimizes the deviations of MCMM energies from single-point accurate energies for a few points on both the convex and concave sides of the MEP. On the one hand it is encouraging that we obtained useful accuracy in previous work even without such optimization of MM parameters. On the other hand, it is even more encouraging that, as we will see below, even such economical partial optimization of the MM parameters in the present work gives dramatic improvement. The use of a softer function in (1) makes 
the matrix elements $V_{11}, V_{22}$, and $V_{12}$ smaller in the saddle point region and eliminates the problems associated with the appearance of artificial energy wells encountered in the previous work. This will be discussed in Section 3 .

We note that if further adjustment were necessary one could adjust $r_{o}$ instead of $D$, if desired. We have not tested other functional forms for the van der Waals energy, and we restricted ourselves to the use of eq. 2 because it is based on the standard MM3 force field, and it leads to rather accurate final results. Another strategy one might employ to reduce the magnitude of $V_{11}$ and $V_{22}$ near the saddle point is to replace the harmonic or almost-harmonic bond stretching terms (these terms dominate $V^{\prime}$ at geometries where it is large in Figure 1) by Morse potentials, which are more realistic for large bond extensions. One must however be careful to ensure that $V_{11}$ and $V_{22}$ both exceed the Born-Oppenheimer potential energy at all geometries. If not, $V_{12}$ becomes imaginary, and one cannot fit the Born-Oppenheimer surface with a real $V_{12}$. Thus there is a tradeoff. One wants $V_{11}$ and $V_{22}$ to be steep enough to avoid this problem but not so steep as to make the fit unstable or to yield unphysical results at geometries away from the Hessian input points.

\section{MCMM surfaces and rate constants}

For the present purposes, we consider a PES to be converged if it yields converged rate constants. Rate constants for reactions R1-R3 were calculated using MCMM PESs and compared to direct dynamics calculations in which potential energies and their derivatives are computed quantum mechanically on the fly. These rate constants (see Tables 2-4) were obtained by variational transition state theory with multidimensional tunneling (VTST/MT). ${ }^{38-45}$ The direct dynamics results used for comparison are taken from the previous work. ${ }^{30,31}$ The electronic structure methods used in the direct dynamics calculations ${ }^{30,} 31$ were MP2(fc)/6-31G(d) ${ }^{46}$ for R1 and MPW1K/6-31+G(d,p) $)^{47}$ for R2 and R3, and we used the same methods to generate data at the Shepard points. 
For consistency, we use the same dynamical algorithms to calculate MEPs and the vibrationally adiabatic energy curves as employed previously. ${ }^{30}$ The electronic structure calculations to obtain the input for the MCMM surfaces were performed with the Gaussian $03^{48}$ suite of programs. MCMM calculations were carried out with a modified MC-TINKER code, and the dynamics calculations on the MCMM surfaces were performed using TINKERATE ${ }^{49}$ which interfaces the VTST/MT code POLYRATE ${ }^{50}$ to MC-TINKER.

In keeping with the previous work, the results shown in Tables 1-5 are based on the standard strategy that was presented earlier ${ }^{30}$ for placement of Shepard points. In addition to the MCMM-0 estimate that uses only information at stationary points and the MCMM-10 scheme that was recommended ${ }^{30}$ to converge $k^{C V T / L C T}$, the results with some intermediate numbers of nonstationary points are also shown. All results presented in Tables 2-5 were obtained with $D=0.01$.

Tables 2-5 show that the canonical variational transition state rate constants, $k^{C V T}$, are well converged using the MCMM-0 PESs. The deviations of the MCMM- $N$ rate constants from their direct dynamics counterparts (shown as mean unsigned percentage errors (MUPEs) in Table 5) sometimes get larger when the number of Shepard points is increased. This happens due primarily to the interpolative noise in the frequencies ${ }^{1}$ that are used to calculate the vibrationally adiabatic ground-state potential energy curve. As we mentioned before ${ }^{30}$ we consider convergence of rate constants to better than $25 \%$ to be very good, keeping in mind that electronic structure calculations and, in fact, the experiments are seldom more accurate.

It is of special interest to examine the success the MCMM method in reproducing the direct dynamics rate constants including tunneling because these are sensitive to more than the potential in a localized dynamical bottleneck region. We consider zero-, small-, and large-curvature $\left(\mathrm{ZCT},{ }^{39} \mathrm{SCT},{ }^{41,42} \mathrm{LCT}^{41,43,45}\right)$ approximations as 
well as microcanonically optimized multidimensional tunneling $\left(\mu O M T^{43,45}\right)$, which involves accepting the larger of the SCT and LCT results at each total energy. For large-curvature tunneling, we consider both the full LCT calculation and a restricted one, $\operatorname{LCT}(0)$, where only tunneling into the ground-state diabatic accepting mode is considered. Convergence of $k^{C V T / L C T}$ and $k^{C V T / \mu O M T}$ are particularly interesting because they depend on the quality of the PES over the broadest region, including points in the reaction swath that are too far from the MEP to be represented by a power series in deviations from the MEP. As such, LCT and $\mu O M T$ calculations are sensitive to the semiglobal shape of the PES, rather than only to the potential near the MEP. In the previous work, ${ }^{30,31}$ large-curvature tunneling was poorly described on MCMM- $N$ PESs with $N<8$ due to inaccurate PESs far away from the reaction path when all Shepard points are near the MEP. However, for all reactions considered in this paper, even MCMM-0 reproduces $k^{C V T / Z C T}, k^{C V T / S C T}$, and $k^{C V T / L C T}$ of the direct dynamics calculations reasonably well. These differences can be clearly seen by comparing the MUPEs for these values calculated using MCMM-0 PES with both new and old parameterizations. In particular, the corresponding errors are 48 (new) vs. 85 (old) $\left(k^{C V T / Z C T}\right)$ and 23 (new) vs. 110 (old) $\left(k^{C V T / S C T}\right)$ for R1; 12 (new) vs. $>5000$ (old) $\left(k^{C V T / Z C T}\right)$ and 18 (new) vs. $>5000$ (old) $\left(k^{C V T / S C T}\right.$ ) for R2; 6 (new) vs. 48 (old) $\left(k^{C V T / Z C T}\right)$ and 18 (new) vs. 490 (old) $\left(k^{C V T / S C T}\right)$ for R3. While the MCMM-0 esimates for $k^{C V T / L C T}$ using old parametrization are unreliable (cf. Tables 4, 6, and 7 of Ref. 30), the corresponding values obtained employing the partly optimized MM are reasonably accurate, and they are listed in Table 5. Adding supplementary points does not necessarily improve the results, indicating that the rate constants are already well converged in the MCMM-0 run. The large-curvature tunneling contributions into the vibrationally excited versus the ground state are reproduced well for R1 in the MCMM-10 run, as indicated by the magnitudes of $k^{C V T / L C T}$ versus $k^{C V T / L C T(0)}$ shown 
in Table 2. For R2, the tunneling into excited states is already well reproduced in the MCMM-0 run. In the past work, ${ }^{30,31}$ it was necessary to place electronic structure data points near the representative large-curvature tunneling path in order to get meaningful $k^{C V T / L C T}$ (cf. Tables 4-11 of Ref. 30) because of the presence of artificial energy wells (cf. Table 1) on the concave side of the MEP that resulted in unphysically large LCT transmission coefficients. ${ }^{30}$ The presence of these wells is not however, a consequence of a failure of the interpolation method, but rather resulted from the overestimation of $V_{v d W}(r)$ as we discussed above. To illustrate the shapes of the MCMM PESs, Figures 2-4 display two-dimensional sections through multidimensional PESs for R1-R3 plotted as functions of the two stretching coordinates, namely, the bond-breaking and bond-making distances. Starting from MCMM-0, the MCMM PESs exhibit potential maxima at about $r_{B r H}=1.59, r_{C l H}=1.57(\mathrm{R} 1), r_{C H}=1.28, r_{O H}=1.22(\mathrm{R} 2)$, and $r_{C H}=1.26, r_{N H}=1.31$ (R3), respectively, in good accord with the electronic structure results ${ }^{30,31}$ and they show no artificial wells on the concave sides of the reaction paths.

\section{Concluding remarks}

We conclude that the MCMM-0 estimates of the rate constants including tunneling are reasonably accurate when appropriate MM potentials are used in MCMM. The agreement with direct dynamics of $k^{C V T / L C T}$ calculated using MCMM-0 PES is remarkable, indicating that MCMM-0 describes the shape of the PES reasonably well not only near the reaction path but also in the large-curvature-tunneling swath of the hydrogen-transfer reactions. The previously proposed strategy for placement of supplementary points works well not only for the originally employed MM parameters but also for the MCMM surfaces with improved MM parameters; however, the interpolated PESs are now equally accurate with fewer points. In fact, the results are not very sensitive to the location of Shepard points on the MEP, and the data points can alternatively be placed at locations where more input seems to be needed, e.g., at a 
spike of the vibrationally adiabatic ground-state potential energy curve, if one encounteres such a spike, or in a flat region if the MEP becomes too flat for following the negative gradient.

One reason why the MCMM method is so powerful is that it builds on previously calibrated MM potentials for nonreactive degrees of freedom. Therefore, it is a very encouraging finding of this study that when these MM potentials in reactive coordinates are roughly optimized for MCMM (which requires only a couple of single-point energy calculations), even the most economical MCMM-0 calculations provide a useful approximation of the expensive full dynamics results for both small-curvature tunneling and large-curvature tunneling. This means that only one high-level electronic structure Hessian (at the saddle point) is needed to get a reasonable estimate for rate constants. These results suggest that the MCMM method is a computationally very efficient method for constructing PESs for polyatomic reactive systems.

\section{Acknowledgement}

This work was supported by the U.S. Department of Energy, Office of Basic Energy Sciences and is also supported in part by the Air Force office of Scientific Research by a Small Business Technology Transfer grant to Scientific Applications \& Research Assoc., Inc. We thank Dr. Hai Lin for discussions. 


\section{References}

[1] Kim, Y.; Corchado, J. C.; Villà, J.; Xing, X., Truhlar, D. G. J. Chem. Phys. 2000, 112, 2718.

[2] Olson, W.; Flory, P. J. Biopolymers 1972, 11, 25.

[3] Burkert, U.; Allinger, N. L. Molecular Mechanics; American Chemical Society: Washington, 1984.

[4] Weiner, S. J.; Kollman, P. A.; Case, D. A.; Singh, C.; Ghio, C.; Alagona, G.; Profeta, S.; Weiner, P. Am. Chem. Soc. 1984, 106, 765.

[5] Hagler, A. T.; Ewig, C. S. Computer Phys. Commun. 1994, 84, 131.

[6] Warshel, A.; Weiss, R. M. J. Am. Chem. Soc. 1980, 102, 6218.

[7] London, F. Z. Electrochem. 1929, 35, 552.

[8] Eyring, H.; Polanyi, M. Z. Physik. Chem. 1931, B12, 279.

[9] Ellison, F. O. J. Am. Chem. Soc. 1963, 85, 3540.

[10] Porter, R. N.; Karplus, M. J. Chem. Phys. 1964, 40, 1105.

[11] Raff, L. M.; Stivers, L.; Porter, R. N.; Thompson, D. L.; Sims, L. B. J. Chem. Phys. 1970, 52, 3449.

[12] Blais, N. C.; Truhlar, D. G. J. Chem. Phys. 1973, 58, 1090.

[13] Raff, L. M. J. Chem. Phys. 1974, 60, 2220.

[14] Tully, J. C. In Semiempirical Methods of Electronic Structure Theory, Part A: Techniques; Segal, G. A., Ed.; Plenum: New York, 1977; p 173. 
[15] Truhlar, D. G.; Wyatt, R. E. Adv. Chem. Phys. 1977, 36, 141.

[16] Kuntz, P. J. In Atom-Molecule Collision Theory; Bernstein, R. B., Ed.; Plenum: New York, 1979; p 79.

[17] Faist, M. B.; Muckerman, J. T. J. Chem. Phys. 1979, 71, 225.

[18] Warshel, A.; Sussman, F.; Hwang, J. K. J. Mol. Biol. 1988, 201, 139.

[19] Warshel, A. Computer Modeling of Chemical Reactions in Enzymes and Solutions; John Wiley \& Sons: New York, 1991.

[20] Yadav, A.; Jackson, R. M.; Holbrook, J. J.; Warshel, A. J. Am. Chem. Soc. 1991, 113, 4800.

[21] Åqvist, J.; Warshel, A. Chem. Rev. 1993, 93, 2523.

[22] Åqvist, J. In Computational Approaches to Biochemical Reactivity; Naray-Szabo, G.; Warshel, A., Eds.; Kluwer Academic: Dordrecht, 1997; Vol. 19; p 341.

[23] Shaik, S.; Shurki, A. Angew. Chem. Int. Ed. Engl., 1997, 36, 2205.

[24] Chang, Y. T.; Miller, W. H. J. Phys. Chem. 1990, 94, 5884.

[25] Chang, Y. T.; Minichino, C.; Miller, W. H. J. Chem. Phys. 1992, 96, 4341.

[26] Schlegel, H. B.; Sonnenberg, J. L. J. Chem. Theor. Comput. 2006, 2, 905.

[27] Ischtwan, J.; Collins, M. A. J. Chem. Phys. 1994, 100, 8080.

[28] Nguyen, K. A.; Rossi, I.; Truhlar, D. G. J. Chem. Phys. 1995, $103,5522$.

[29] Tishchenko, O.; Truhlar, D. G., J. Chem. Theor. Comput. Submitted for publication. 
[30] Albu, T.V.; Corchado, J.C.; Truhlar, D.G. J. Phys. Chem. A 2001, 105, 8465.

[31] Lin, H.; Pu, J.; Albu, T.V.; Truhlar, D.G. J. Phys. Chem. A 2004, 108, 4112.

[32] Lin, H.; Zhao, Y.; Tishchenko, O.; Truhlar, D.G., J. Chem. Theor. Comp., 2006, 2, 1237.

[33] Allinger, N.C. J. Am. Chem. Soc. 1977, 99, 8127.

[34] Allinger, N.C.; Yuh, Y.H.; Lii, J.-H. J. Am. Chem. Soc. 1998, 111, 8551.

[35] Lii,J.-H.; Allinger, N. L. J. Am. Chem. Soc. 1989, 111, 8566.

[36] Lii,J.-H.; Allinger, N. L. J. Am. Chem. Soc.1989, 111, 8576.

[37] Albu, T. V.; Corchado, J. C.; Kim, Y.; Villà, J.; Xing, J.; Lin, H.; Truhlar, D. G. MC-TINKER 1.0.1, University of Minnesota, Minneapolis, MN, 2003.

[38] Garrett, B. C.; Truhlar, D. G. J. Chem. Phys. 1979, 70, 1593.

[39] Truhlar, D. G.; Isaacson, A. D.; Skodje, R. T.; Garrett, B. C. J. Phys. Chem. 1982, 86, 2252. 1983, 87, $4554(\mathrm{E})$.

[40] Truhlar, D. G.; Gordon, M. S. Science 1990, 249, 491.

[41] Lu, D.-H.; Truong, T. N.; Melissas, V. S.; Lynch, G. C.; Liu, Y.- P.; Garrett, B. C.; Steckler, R.; Isaacson, A. D.; Rai, S. N.; Hancock, G. C.; Lauderdale, J. G.; Joseph, T.; Truhlar, D. G. Comput. Phys. Commun. 1992, 71, 235.

[42] Liu, Y.-P.; Lynch, G. C.; Truong, T. N.; Truhlar, D. G.; Garrett, B. C. J. Amer. Chem. Soc. 1993, 115, 2408.

[43] Liu, Y.-P.; Lu, D.-h.; González-Lafont, A.; Truhlar, D. G.; Garrett, B. C. J. Amer. Chem. Soc. 1993, 115, 7806. 
[44] Truhlar, D. G.; Garrett, B. C.; Klippenstein, S. J. J. Phys. Chem. 1996, 100, 12771.

[45] Fernández-Ramos, A.; Truhlar, D. G. J. Chem. Phys. 2001, 114, 1491.

[46] Pople, J.A.; Binkley, J.S.; Seeger, L. Int. J. Quantum Chem.,Symp. 1976, 10, 1.

[47] Lynch, B. J.; Fast, P. L.; Harris, M.; Truhlar, D. G. J. Phys. Chem. A 2000, $104,4811$.

[48] Frisch, M. J.; Trucks, G. W.; Schlegel, H. B.; Scuseria, G. E.; Robb, M. A.; Cheeseman, J. R.; Montgomery, J. A., Jr.; Vreven, T.; Kudin, K. N.; Burant, J. C.; Millam, J. M.; Iyengar, S. S.; Tomasi, J.; Barone, V.; Mennucci, B.; Cossi, M.; Scalmani, G.; Rega, N.; Petersson, G. A.; Nakatsuji, H.; Hada, M.; Ehara, M.; Toyota, K.; Fukuda, R.; Hasegawa, J.; Ishida, M.; Nakajima, T.; Honda, Y.; Kitao, O.; Nakai, H.; Klene, M.; Li, X.; Knox, J. E.; Hratchian, H. P.; Cross, J. B.; Bakken, V.; Adamo, C.; Jaramillo, J.; Gomperts, R.; Stratmann, R. E.; Yazyev, O.; Austin, A. J.; Cammi, R.; Pomelli, C.; Ochterski, J. W.; Ayala, P. Y.; Morokuma, K.; Voth, G. A.; Salvador, P.; Dannenberg, J. J.; Zakrzewski, V. G.; Dapprich, S.; Daniels, A. D.; Strain, M. C.; Farkas, O.; Malick, D. K.; Rabuck, A. D.; Raghavachari, K.; Foresman, J. B.; Ortiz, J. V.; Cui, Q.; Baboul, A. G.; Clifford, S.; Cioslowski, J.; Stefanov, B. B.; Liu, G.; Liashenko, A.; Piskorz, P.; Komaromi, I.; Martin, R. L.; Fox, D. J.; Keith, T.; Al-Laham, M. A.; Peng, C. Y.; Nanayakkara, A.; Challacombe, M.; Gill, P. M. W.; Johnson, B.; Chen, W.; Wong, M. W.; Gonzalez, C.; Pople, J. A. Gaussian 03, revision C.01; Gaussian, Inc.: Wallingford, CT, 2004.

[49] Albu, T. V.; Corchado, J. C.; Kim, Y.; Villa, J.; Xing, J.; Lin, H.; Truhlar, D. G. mC-Tinkerate 9.1, University of Minnesota, Minneapolis, MN, 2003. 
[50] Corchado, J. C.; Chuang, Y.-Y.; Fast, P. L.; Villa, J.; Hu, W.-P.; Liu, Y.-P.; Lynch, G. C.; Nguyen, K. A.; Jackels, C. F.; Melissas, V. S.; Lynch, B. J.; Rossi, I.; Coitiño, E. L.; Fernández-Ramos, A.; Pu, J.; Albu, T. V.; Steckler, R.; Garrett, B. C.; Isaacson, A. D.; Truhlar, D. G. Polyrate 9.1, University of Minnesota, Minneapolis, MN, 2002. 
Table 1: Values of the matrix elements of $\mathbf{V}(\mathbf{q})$ of reaction $\mathrm{R} 3$ and the lowest eigenvalue $V$ versus target energy, with different values of $D$ for two different values $N_{H}$ of the number of electronic structure Hessians. ${ }^{1}$ The data are shown at a geometry $\left(r_{C H}=1.35, r_{N H}=1.35\right)$ close to the saddle point, and at two representative geometries on the concave $\left(r_{C H}=1.50\right.$, $\left.r_{N H}=1.50\right)$ and convex $\left(r_{C H}=1.10, r_{N H}=1.10\right)$ sides of the MEP. Energies are in $\mathrm{kcal} / \mathrm{mol}$, relative to the reactant asymptote.

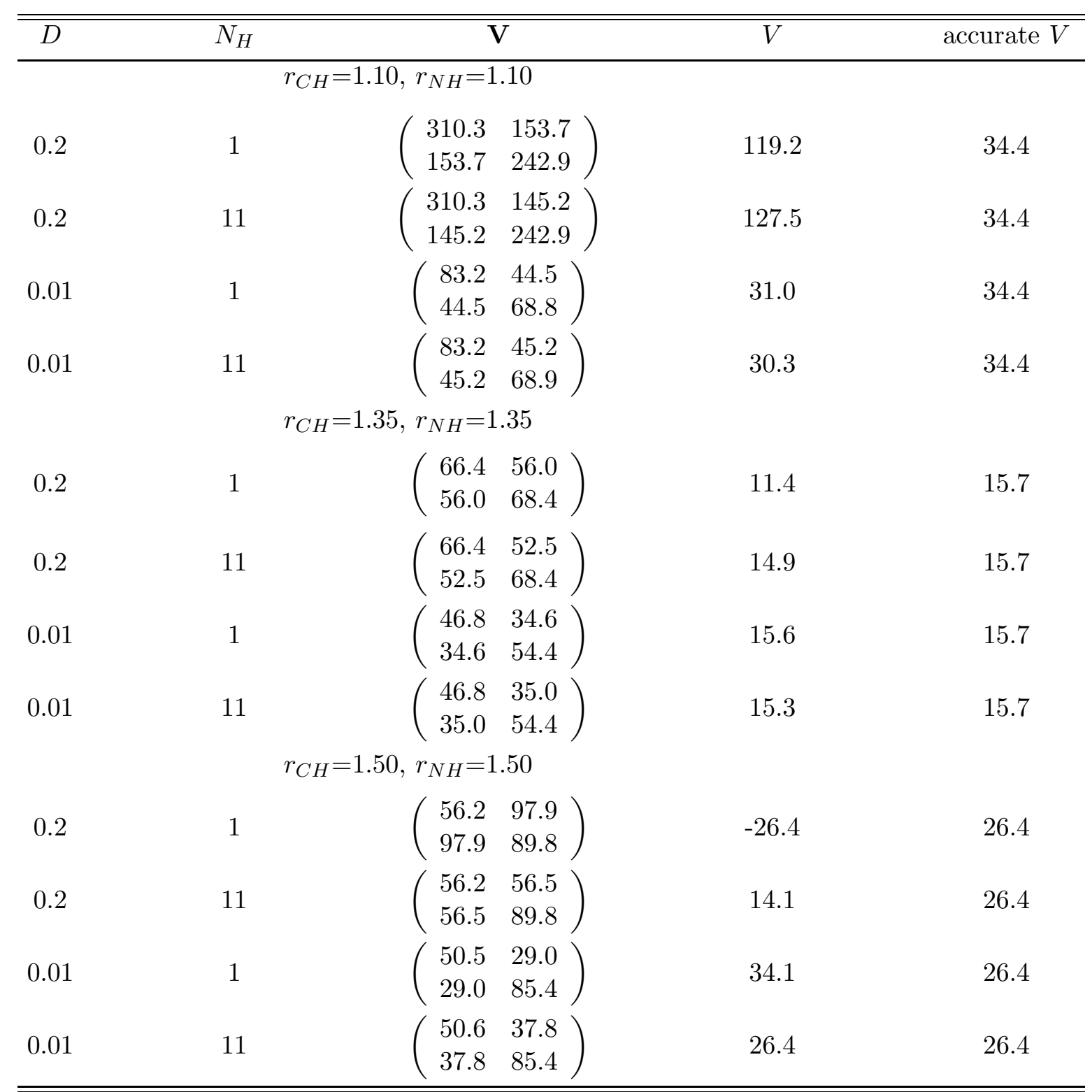

$\overline{1 \text { The location of the data points for } N_{H}=11 \text { (which is called MCMM-10) is determined }}$ according to the prescription of Ref. 30 . 
Table 2: Rate Constants $\left(\mathrm{cm}^{3} \cdot \mathrm{molecule}^{-1} \cdot \mathrm{s}^{-1}\right)$ by Direct Dynamics and MCMM for R1.

\begin{tabular}{|c|c|c|c|c|c|c|}
\hline$\overline{\mathrm{T}(\mathrm{K})}$ & CVT & $\begin{array}{l}\mathrm{CVT} / \\
\mathrm{ZCT}\end{array}$ & $\begin{array}{l}\text { CVT/ } \\
\text { SCT }\end{array}$ & $\begin{array}{c}\mathrm{CVT} / \\
\operatorname{LCT}(0)\end{array}$ & $\begin{array}{l}\mathrm{CVT} / \\
\mathrm{LCT}\end{array}$ & $\begin{array}{l}\mathrm{CVT} / \\
\mu \mathrm{OMT}\end{array}$ \\
\hline & \multicolumn{6}{|c|}{ Direct Dynamics } \\
\hline 300 & $2.09 \cdot 10^{-18}$ & $6.92 \cdot 10^{-18}$ & $3.03 \cdot 10^{-17}$ & $1.45 \cdot 10^{-17}$ & $1.61 \cdot 10^{-17}$ & $3.05 \cdot 10^{-17}$ \\
\hline 400 & $1.40 \cdot 10^{-16}$ & $2.20 \cdot 10^{-16}$ & $5.05 \cdot 10^{-16}$ & $2.90 \cdot 10^{-16}$ & $3.31 \cdot 10^{-16}$ & $5.10 \cdot 10^{-16}$ \\
\hline \multirow[t]{2}{*}{600} & $9.78 \cdot 10^{-15}$ & $1.13 \cdot 10^{-14}$ & $1.63 \cdot 10^{-14}$ & $1.23 \cdot 10^{-14}$ & $1.34 \cdot 10^{-14}$ & $1.65 \cdot 10^{-14}$ \\
\hline & \multicolumn{6}{|c|}{ MCMM-0 } \\
\hline 300 & $2.41 \cdot 10^{-18}$ & $9.15 \cdot 10^{-18}$ & $1.80 \cdot 10^{-17}$ & $1.40 \cdot 10^{-17}$ & $1.41 \cdot 10^{-17}$ & $1.81 \cdot 10^{-17}$ \\
\hline 400 & $1.64 \cdot 10^{-16}$ & $3.44 \cdot 10^{-16}$ & $5.01 \cdot 10^{-16}$ & $4.15 \cdot 10^{-16}$ & $4.17 \cdot 10^{-16}$ & $5.05 \cdot 10^{-16}$ \\
\hline \multirow[t]{2}{*}{600} & $1.29 \cdot 10^{-14}$ & $1.75 \cdot 10^{-14}$ & $2.06 \cdot 10^{-14}$ & $1.87 \cdot 10^{-14}$ & $1.87 \cdot 10^{-14}$ & $2.07 \cdot 10^{-14}$ \\
\hline & \multicolumn{6}{|c|}{ MCMM-1 } \\
\hline 300 & $2.02 \cdot 10^{-18}$ & $6.29 \cdot 10^{-18}$ & $1.47 \cdot 10^{-17}$ & $1.12 \cdot 10^{-17}$ & $1.12 \cdot 10^{-17}$ & $1.48 \cdot 10^{-17}$ \\
\hline 400 & $1.38 \cdot 10^{-16}$ & $2.45 \cdot 10^{-16}$ & $4.00 \cdot 10^{-16}$ & $3.19 \cdot 10^{-16}$ & $3.19 \cdot 10^{-16}$ & $4.00 \cdot 10^{-16}$ \\
\hline \multirow{2}{*}{600} & $1.03 \cdot 10^{-15}$ & $1.30 \cdot 10^{-15}$ & $1.61 \cdot 10^{-15}$ & $1.42 \cdot 10^{-15}$ & $1.42 \cdot 10^{-15}$ & $1.61 \cdot 10^{-15}$ \\
\hline & \multicolumn{6}{|c|}{ MCMM-5 } \\
\hline 300 & $1.93 \cdot 10^{-18}$ & $6.79 \cdot 10^{-18}$ & $2.08 \cdot 10^{-17}$ & $1.50 \cdot 10^{-17}$ & $1.57 \cdot 10^{-17}$ & $2.08 \cdot 10^{-17}$ \\
\hline 400 & $1.33 \cdot 10^{-16}$ & $2.48 \cdot 10^{-16}$ & $4.43 \cdot 10^{-16}$ & $3.43 \cdot 10^{-16}$ & $3.65 \cdot 10^{-16}$ & $4.43 \cdot 10^{-16}$ \\
\hline \multirow[t]{2}{*}{600} & $1.00 \cdot 10^{-14}$ & $1.28 \cdot 10^{-14}$ & $1.63 \cdot 10^{-15}$ & $1.42 \cdot 10^{-15}$ & $1.49 \cdot 10^{-15}$ & $1.63 \cdot 10^{-15}$ \\
\hline & \multicolumn{6}{|c|}{ MCMM-10 } \\
\hline 300 & $1.83 \cdot 10^{-18}$ & $6.11 \cdot 10^{-18}$ & $2.28 \cdot 10^{-17}$ & $1.28 \cdot 10^{-17}$ & $1.40 \cdot 10^{-17}$ & $2.29 \cdot 10^{-17}$ \\
\hline 400 & $1.22 \cdot 10^{-16}$ & $2.19 \cdot 10^{-16}$ & $4.43 \cdot 10^{-16}$ & $2.91 \cdot 10^{-16}$ & $3.24 \cdot 10^{-16}$ & $4.44 \cdot 10^{-16}$ \\
\hline 600 & $8.98 \cdot 10^{-14}$ & $1.13 \cdot 10^{-14}$ & $1.52 \cdot 10^{-14}$ & $1.23 \cdot 10^{-14}$ & $1.32 \cdot 10^{-14}$ & $1.52 \cdot 10^{-14}$ \\
\hline
\end{tabular}


Table 3: Rate Constants $\left(\mathrm{cm}^{3} \cdot \mathrm{molecule}^{-1} \cdot \mathrm{s}^{-1}\right)$ by Direct Dynamics and MCMM for R2.

\begin{tabular}{|c|c|c|c|c|c|c|}
\hline$\overline{\mathrm{T}(\mathrm{K})}$ & CVT & $\begin{array}{l}\text { CVT/ } \\
\mathrm{ZCT}\end{array}$ & $\begin{array}{l}\mathrm{CVT} / \\
\mathrm{SCT}\end{array}$ & $\begin{array}{c}\mathrm{CVT} / \\
\mathrm{LCT}(0)\end{array}$ & $\begin{array}{l}\mathrm{CVT} / \\
\mathrm{LCT}\end{array}$ & $\begin{array}{l}\mathrm{CVT} / \\
\mu \mathrm{OMT}\end{array}$ \\
\hline & \multicolumn{6}{|c|}{ Direct Dynamics } \\
\hline 300 & $2.59 \cdot 10^{-16}$ & $4.84 \cdot 10^{-16}$ & $7.64 \cdot 10^{-16}$ & $5.39 \cdot 10^{-16}$ & $6.23 \cdot 10^{-16}$ & $7.65 \cdot 10^{-16}$ \\
\hline 400 & $5.36 \cdot 10^{-14}$ & $7.55 \cdot 10^{-15}$ & $9.87 \cdot 10^{-15}$ & $7.90 \cdot 10^{-15}$ & $8.64 \cdot 10^{-15}$ & $9.88 \cdot 10^{-15}$ \\
\hline \multirow[t]{2}{*}{600} & $1.39 \cdot 10^{-13}$ & $1.59 \cdot 10^{-13}$ & $1.80 \cdot 10^{-13}$ & $1.62 \cdot 10^{-13}$ & $1.69 \cdot 10^{-13}$ & $1.80 \cdot 10^{-13}$ \\
\hline & \multicolumn{6}{|c|}{ MCMM- 0} \\
\hline 300 & $2.90 \cdot 10^{-16}$ & $6.08 \cdot 10^{-16}$ & $1.04 \cdot 10^{-15}$ & $7.42 \cdot 10^{-16}$ & $8.20 \cdot 10^{-16}$ & $1.04 \cdot 10^{-15}$ \\
\hline 400 & $5.49 \cdot 10^{-14}$ & $8.31 \cdot 10^{-14}$ & $1.14 \cdot 10^{-15}$ & $9.03 \cdot 10^{-15}$ & $9.55 \cdot 10^{-15}$ & $1.14 \cdot 10^{-14}$ \\
\hline \multirow[t]{2}{*}{600} & $1.31 \cdot 10^{-13}$ & $1.57 \cdot 10^{-13}$ & $1.82 \cdot 10^{-13}$ & $1.61 \cdot 10^{-13}$ & $1.65 \cdot 10^{-13}$ & $1.82 \cdot 10^{-13}$ \\
\hline & \multicolumn{6}{|c|}{ MCMM-1 } \\
\hline 300 & $3.33 \cdot 10^{-16}$ & $5.10 \cdot 10^{-16}$ & $7.28 \cdot 10^{-16}$ & $5.59 \cdot 10^{-16}$ & $5.80 \cdot 10^{-16}$ & $7.30 \cdot 10^{-16}$ \\
\hline 400 & $6.21 \cdot 10^{-14}$ & $1.77 \cdot 10^{-15}$ & $9.43 \cdot 10^{-15}$ & $8.02 \cdot 10^{-15}$ & $8.20 \cdot 10^{-15}$ & $9.43 \cdot 10^{-15}$ \\
\hline \multirow{2}{*}{600} & $1.46 \cdot 10^{-13}$ & $1.58 \cdot 10^{-13}$ & $1.72 \cdot 10^{-13}$ & $1.60 \cdot 10^{-13}$ & $1.61 \cdot 10^{-13}$ & $1.72 \cdot 10^{-13}$ \\
\hline & \multicolumn{6}{|c|}{ MCMM-2 } \\
\hline 300 & $3.12 \cdot 10^{-16}$ & $4.89 \cdot 10^{-16}$ & $6.99 \cdot 10^{-16}$ & $5.40 \cdot 10^{-16}$ & $5.80 \cdot 10^{-16}$ & $7.30 \cdot 10^{-16}$ \\
\hline 400 & $5.92 \cdot 10^{-14}$ & $7.50 \cdot 10^{-15}$ & $9.12 \cdot 10^{-15}$ & $7.77 \cdot 10^{-15}$ & $8.20 \cdot 10^{-15}$ & $9.43 \cdot 10^{-15}$ \\
\hline \multirow[t]{2}{*}{600} & $1.41 \cdot 10^{-13}$ & $1.54 \cdot 10^{-13}$ & $1.68 \cdot 10^{-13}$ & $1.56 \cdot 10^{-13}$ & $1.61 \cdot 10^{-13}$ & $1.72 \cdot 10^{-13}$ \\
\hline & \multicolumn{6}{|c|}{ MCMM-10 } \\
\hline 300 & $3.28 \cdot 10^{-16}$ & $6.31 \cdot 10^{-16}$ & $8.88 \cdot 10^{-16}$ & $6.96 \cdot 10^{-16}$ & $7.51 \cdot 10^{-16}$ & $8.91 \cdot 10^{-16}$ \\
\hline 400 & $6.98 \cdot 10^{-15}$ & $1.01 \cdot 10^{-14}$ & $1.23 \cdot 10^{-14}$ & $1.05 \cdot 10^{-14}$ & $1.11 \cdot 10^{-14}$ & $1.23 \cdot 10^{-14}$ \\
\hline 600 & $1.86 \cdot 10^{-13}$ & $2.19 \cdot 10^{-13}$ & $2.41 \cdot 10^{-13}$ & $2.11 \cdot 10^{-13}$ & $2.28 \cdot 10^{-13}$ & $2.41 \cdot 10^{-13}$ \\
\hline
\end{tabular}


Table 4: Rate Constants $\left(\mathrm{cm}^{3} \cdot \mathrm{molecule}^{-1} \cdot \mathrm{s}^{-1}\right)$ by Direct Dynamics and MCMM for R3.

\begin{tabular}{|c|c|c|c|c|c|c|}
\hline$\overline{\mathrm{T}(\mathrm{K})}$ & CVT & $\begin{array}{l}\mathrm{CVT} / \\
\mathrm{ZCT}\end{array}$ & $\begin{array}{l}\text { CVT/ } \\
\text { SCT }\end{array}$ & $\begin{array}{c}\mathrm{CVT} / \\
\operatorname{LCT}(0)\end{array}$ & $\begin{array}{l}\mathrm{CVT} / \\
\mathrm{LCT}\end{array}$ & $\begin{array}{l}\mathrm{CVT} / \\
\mu \mathrm{OMT}\end{array}$ \\
\hline & \multicolumn{6}{|c|}{ Direct Dynamics } \\
\hline 300 & $6.18 \cdot 10^{-22}$ & $3.21 \cdot 10^{-21}$ & $7.57 \cdot 10^{-21}$ & $1.70 \cdot 10^{-20}$ & $1.70 \cdot 10^{-20}$ & $1.77 \cdot 10^{-20}$ \\
\hline 400 & $2.06 \cdot 10^{-19}$ & $5.41 \cdot 10^{-19}$ & $8.65 \cdot 10^{-19}$ & $1.08 \cdot 10^{-18}$ & $1.08 \cdot 10^{-18}$ & $1.16 \cdot 10^{-18}$ \\
\hline \multirow[t]{2}{*}{600} & $9.28 \cdot 10^{-17}$ & $1.45 \cdot 10^{-16}$ & $1.78 \cdot 10^{-16}$ & $1.81 \cdot 10^{-16}$ & $1.81 \cdot 10^{-16}$ & $1.91 \cdot 10^{-16}$ \\
\hline & \multicolumn{6}{|c|}{ MCMM-0 } \\
\hline 300 & $5.28 \cdot 10^{-22}$ & $3.38 \cdot 10^{-21}$ & $5.93 \cdot 10^{-21}$ & $1.87 \cdot 10^{-20}$ & $1.87 \cdot 10^{-20}$ & $1.88 \cdot 10^{-20}$ \\
\hline 400 & $1.76 \cdot 10^{-19}$ & $5.30 \cdot 10^{-19}$ & $7.20 \cdot 10^{-19}$ & $1.23 \cdot 10^{-18}$ & $1.23 \cdot 10^{-18}$ & $1.24 \cdot 10^{-18}$ \\
\hline \multirow[t]{2}{*}{600} & $7.86 \cdot 10^{-17}$ & $1.31 \cdot 10^{-16}$ & $1.50 \cdot 10^{-16}$ & $1.78 \cdot 10^{-16}$ & $1.78 \cdot 10^{-16}$ & $1.80 \cdot 10^{-16}$ \\
\hline & \multicolumn{6}{|c|}{ MCMM-3 } \\
\hline 300 & $5.28 \cdot 10^{-22}$ & $2.78 \cdot 10^{-21}$ & $5.31 \cdot 10^{-21}$ & $6.39 \cdot 10^{-21}$ & $6.39 \cdot 10^{-21}$ & $6.96 \cdot 10^{-21}$ \\
\hline 400 & $1.76 \cdot 10^{-19}$ & $4.69 \cdot 10^{-19}$ & $6.59 \cdot 10^{-19}$ & $7.02 \cdot 10^{-19}$ & $7.02 \cdot 10^{-19}$ & $7.56 \cdot 10^{-19}$ \\
\hline \multirow{2}{*}{600} & $7.86 \cdot 10^{-17}$ & $1.24 \cdot 10^{-16}$ & $1.43 \cdot 10^{-16}$ & $1.44 \cdot 10^{-16}$ & $1.44 \cdot 10^{-16}$ & $1.51 \cdot 10^{-16}$ \\
\hline & \multicolumn{6}{|c|}{ MCMM-7 } \\
\hline 300 & $5.28 \cdot 10^{-22}$ & $2.61 \cdot 10^{-21}$ & $5.31 \cdot 10^{-21}$ & $1.01 \cdot 10^{-20}$ & $1.01 \cdot 10^{-20}$ & $1.04 \cdot 10^{-20}$ \\
\hline 400 & $1.76 \cdot 10^{-19}$ & $4.49 \cdot 10^{-19}$ & $6.54 \cdot 10^{-19}$ & $8.19 \cdot 10^{-19}$ & $8.19 \cdot 10^{-19}$ & $8.62 \cdot 10^{-19}$ \\
\hline \multirow[t]{2}{*}{600} & $7.86 \cdot 10^{-17}$ & $1.21 \cdot 10^{-16}$ & $1.42 \cdot 10^{-16}$ & $1.48 \cdot 10^{-16}$ & $1.48 \cdot 10^{-16}$ & $1.54 \cdot 10^{-16}$ \\
\hline & \multicolumn{6}{|c|}{ MCMM-10 } \\
\hline 300 & $5.28 \cdot 10^{-22}$ & $2.62 \cdot 10^{-21}$ & $5.44 \cdot 10^{-21}$ & $1.03 \cdot 10^{-20}$ & $1.03 \cdot 10^{-20}$ & $1.07 \cdot 10^{-20}$ \\
\hline 400 & $1.76 \cdot 10^{-19}$ & $4.50 \cdot 10^{-19}$ & $6.65 \cdot 10^{-19}$ & $8.24 \cdot 10^{-19}$ & $8.24 \cdot 10^{-19}$ & $8.71 \cdot 10^{-19}$ \\
\hline 600 & $7.86 \cdot 10^{-17}$ & $1.21 \cdot 10^{-16}$ & $1.43 \cdot 10^{-16}$ & $1.49 \cdot 10^{-16}$ & $1.49 \cdot 10^{-16}$ & $1.55 \cdot 10^{-16}$ \\
\hline
\end{tabular}


Table 5: Mean Unsigned Percentage Errors Averaged over Three Temperatures (300K, 400K, and $600 \mathrm{~K})$ for R1-R3.

\begin{tabular}{|c|c|c|c|c|c|c|}
\hline & $\overline{\mathrm{CVT}}$ & $\begin{array}{l}\mathrm{CVT} / \\
\mathrm{ZCT}\end{array}$ & $\begin{array}{c}\text { CVT/ } \\
\text { SCT }\end{array}$ & $\begin{array}{c}\mathrm{CVT} / \\
\operatorname{LCT}(0)\end{array}$ & $\begin{array}{l}\mathrm{CVT} / \\
\mathrm{LCT} \\
\end{array}$ & $\begin{array}{l}\mathrm{CVT} / \\
\mu \mathrm{OMT}\end{array}$ \\
\hline \multicolumn{7}{|c|}{$\mathrm{Cl}+\mathrm{BrH} \rightarrow \mathrm{ClH}+\mathrm{Br}$} \\
\hline MCMM-0 & 21 & 48 & 23 & 33 & 23 & 24 \\
\hline MCMM-1 & 2 & 12 & 25 & 16 & 13 & 25 \\
\hline MCMM-5 & 5 & 9 & 5 & 13 & 8 & 15 \\
\hline MCMM-10 & 11 & 4 & 15 & 4 & 8 & 11 \\
\hline \multicolumn{7}{|c|}{$\mathrm{CH}_{4}+\mathrm{OH} \rightarrow \mathrm{CH}_{3}+\mathrm{H}_{2} \mathrm{O}$} \\
\hline MCMM-0 & 7 & 12 & 18 & 17 & 15 & 18 \\
\hline MCMM-1 & 16 & 3 & 5 & 2 & 6 & 16 \\
\hline MCMM-2 & 11 & 2 & 8 & 2 & 6 & 5 \\
\hline MCMM-10 & 30 & 34 & 25 & 33 & 28 & 25 \\
\hline \multicolumn{7}{|c|}{$\mathrm{CH}_{4}+\mathrm{NH}_{2} \rightarrow \mathrm{CH}_{3}+\mathrm{NH}_{3}$} \\
\hline MCMM-0 & 15 & 6 & 18 & 8 & 8 & 6 \\
\hline MCMM-3 & 15 & 14 & 24 & 39 & 39 & 39 \\
\hline MCMM-7 & 15 & 17 & 25 & 28 & 28 & 29 \\
\hline MCMM-10 & 15 & 17 & 24 & 27 & 27 & 28 \\
\hline
\end{tabular}




\section{Figure Captions}

Figure 1. van der Waals energies of the two valence bond configurations (I for reactants and II for products) of R3 and their largest components that describe the $\mathrm{N} \cdots \mathrm{H}$ and $\mathrm{C} \cdots \mathrm{H}$ interactions plotted as functions of the $r_{C H}$ distance with all internal coordinates fixed at their values at the MPW1K/6-31+G(d,p) saddle point viz. $r_{N H}\left(\right.$ in $\left.\mathrm{NH}_{2}\right)=1.016 \AA, \angle H N H\left(\right.$ in $\left.\mathrm{NH}_{2}\right) \approx 105^{\circ}, r_{C H}\left(\right.$ in $\left.\mathrm{CH}_{4}\right)=1.083 \AA, \angle H C H$ (in $\left.\mathrm{CH}_{3}\right) \approx 113^{\circ}, \angle \mathrm{NH}_{t} \mathrm{C} \approx 171^{\circ}$. $V^{\prime}$ is a sum of all other MM terms except $V_{v d W}(I)$. The corresponding value for configuration II is a constant and is not shown for clarity. Also shown in this Figure is the resonance integral $V_{12}$, using $N_{H}=11$. All values correspond to $D=0.2$ (upper panel) and $D=0.01$ (lower panel) in eq. (2). Geometrically, the lower panel corresponds to the one-dimensional cut through the PESs shown in Figure 4 (see below) at $r_{N H}=1.1 \AA$.

Figure 2. Equipotential contours of the electronic ground state energy $V(\mathbf{q})$ as the lowest eigenvalue of (1) of the MCMM-0 (upper panel) and MCMM-10 (lower panel) PESs of reaction $\mathrm{R} 1$ plotted as a function of $\mathrm{r}(\mathrm{HCl})$ and $\mathrm{r}(\mathrm{HBr})$ bond distances. $\angle C l H B r$ is fixed at $152^{\circ}$. Zero of energy corresponds to the reactant asymptote. Contour labels are in $\mathrm{kcal} / \mathrm{mol}$. Above $21 \mathrm{kcal} / \mathrm{mol}$, contours are equally spaced by $4 \mathrm{kcal} / \mathrm{mol}$.

Figure 3. Same as Figure 2 except for R2 plotted as a function of $\mathrm{r}(\mathrm{CH})$ and $\mathrm{r}(\mathrm{OH})$ bond distances. The remaining geometrical parameters are $r_{O H}(\mathrm{OH})=0.962 \AA, \angle H O H_{t} \approx$ $99.9^{\circ}, r_{C H}\left(\mathrm{CH}_{4}\right)=1.083 \AA, \angle H C H\left(\mathrm{CH}_{3}\right) \approx 113^{\circ}, \angle O H_{t} C=173.7^{\circ}$. Starting at $9 \mathrm{kcal} / \mathrm{mol}$, contours are equally spaced by $2 \mathrm{kcal} / \mathrm{mol}$.

Figure 4. Same as Figure 2 except for $\mathrm{R} 3$ plotted as a function of $\mathrm{r}(\mathrm{NH})$ and $\mathrm{r}(\mathrm{OH})$ bond distances. The remaining internal coordinates are fixed at their values at the MPW1K/6-31+G(d,p) saddle point (see caption in Figure 1). 
Figure 1.
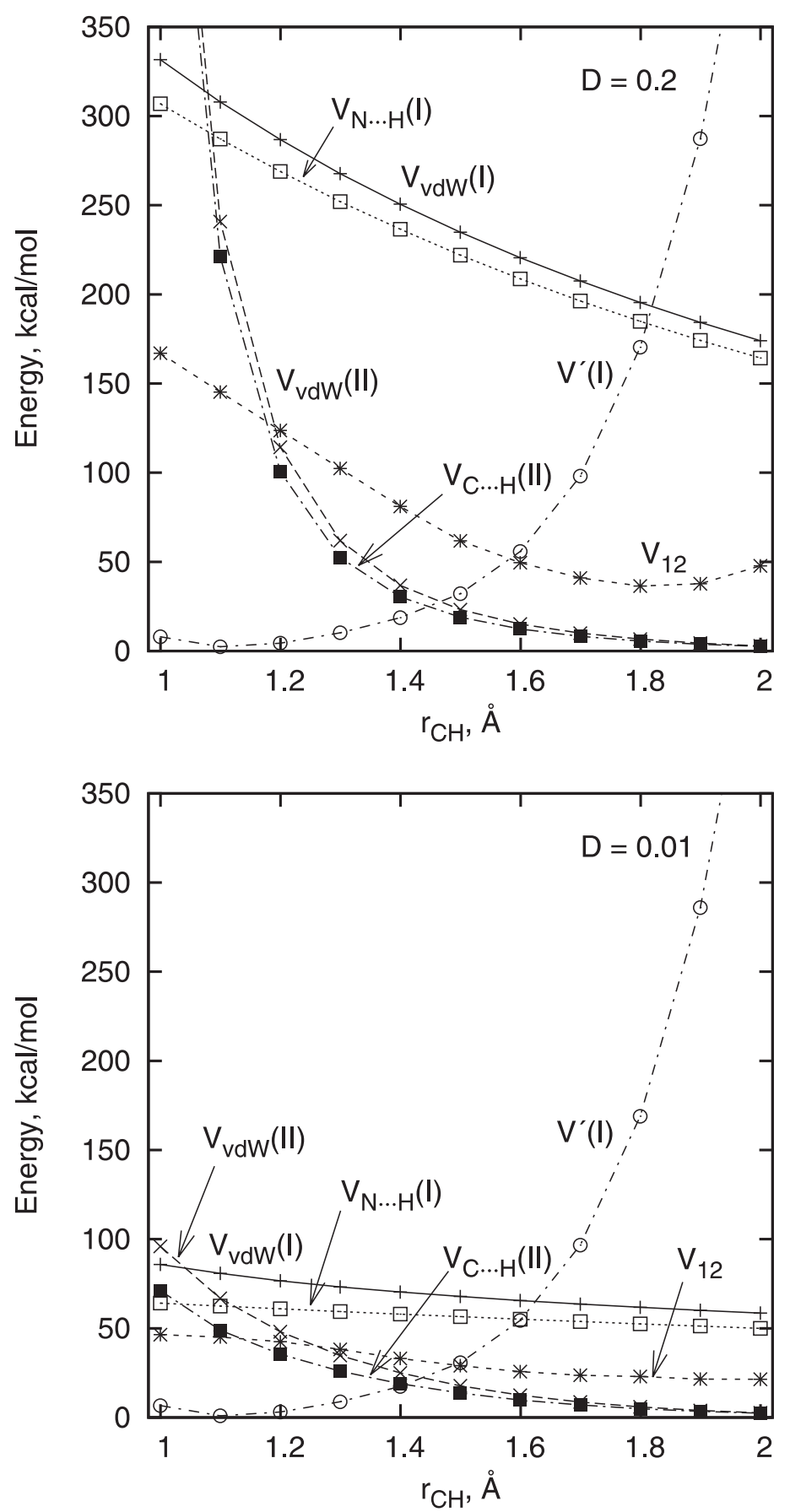
Figure 2.
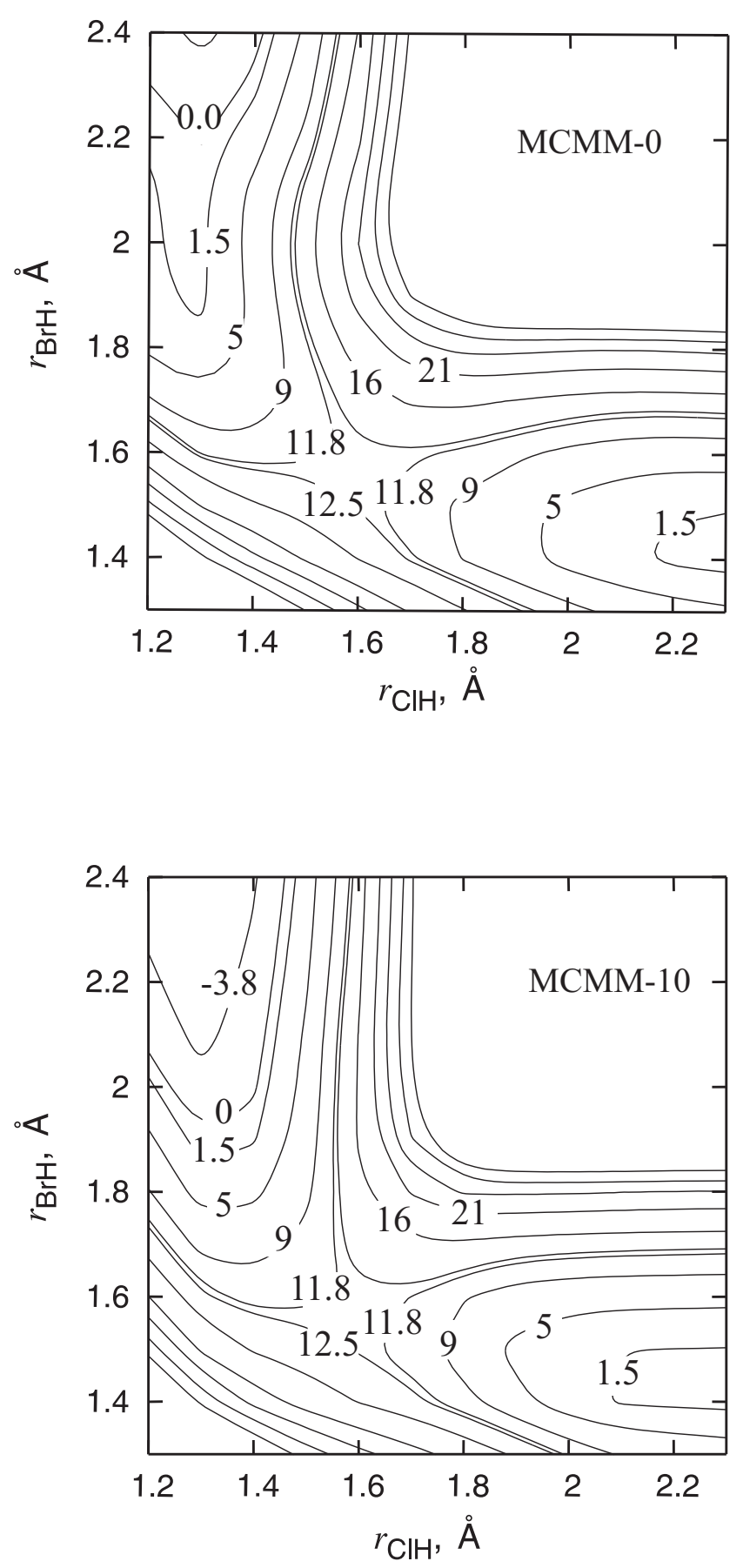
Figure 3.
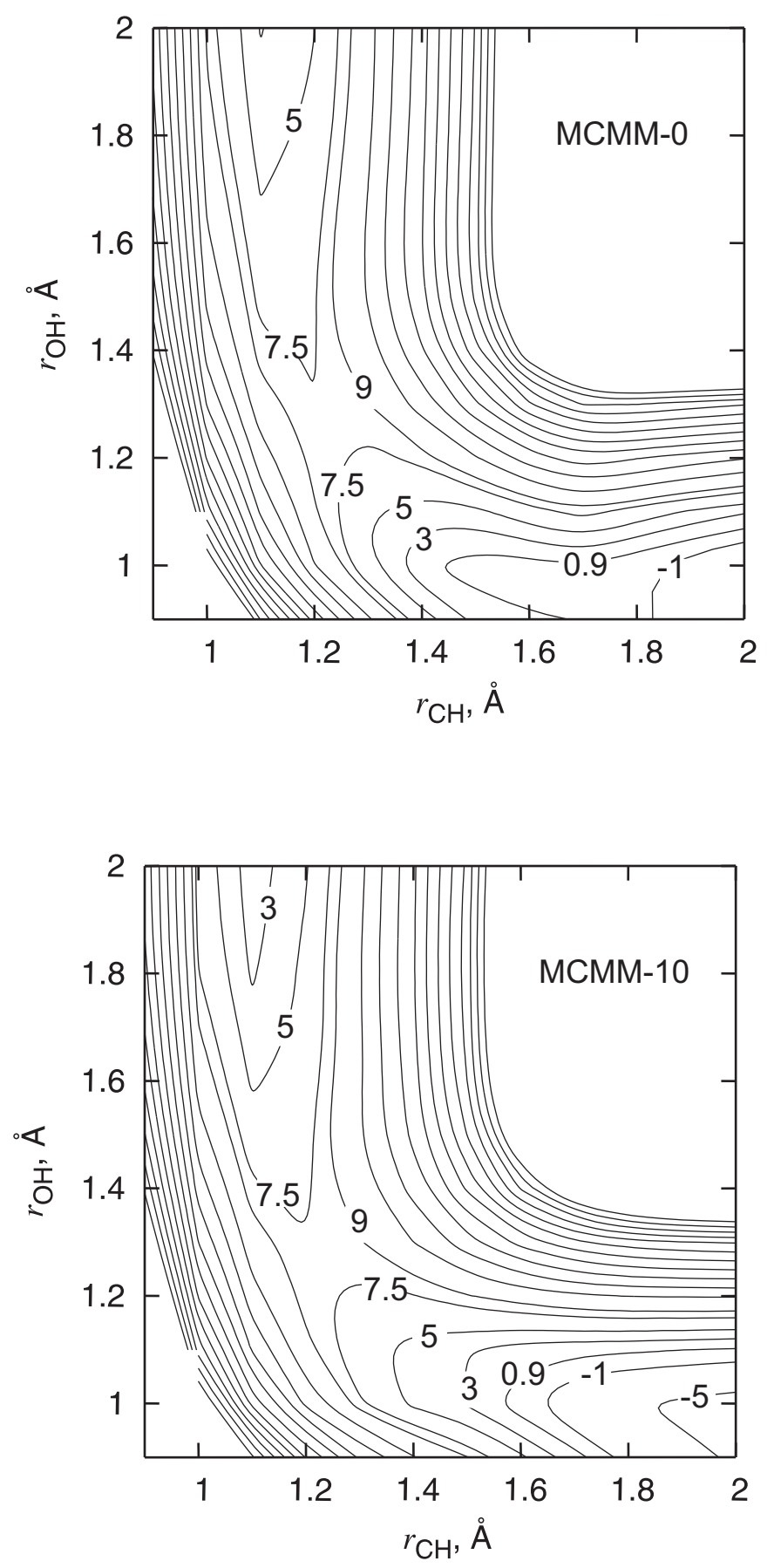
Figure 4 .
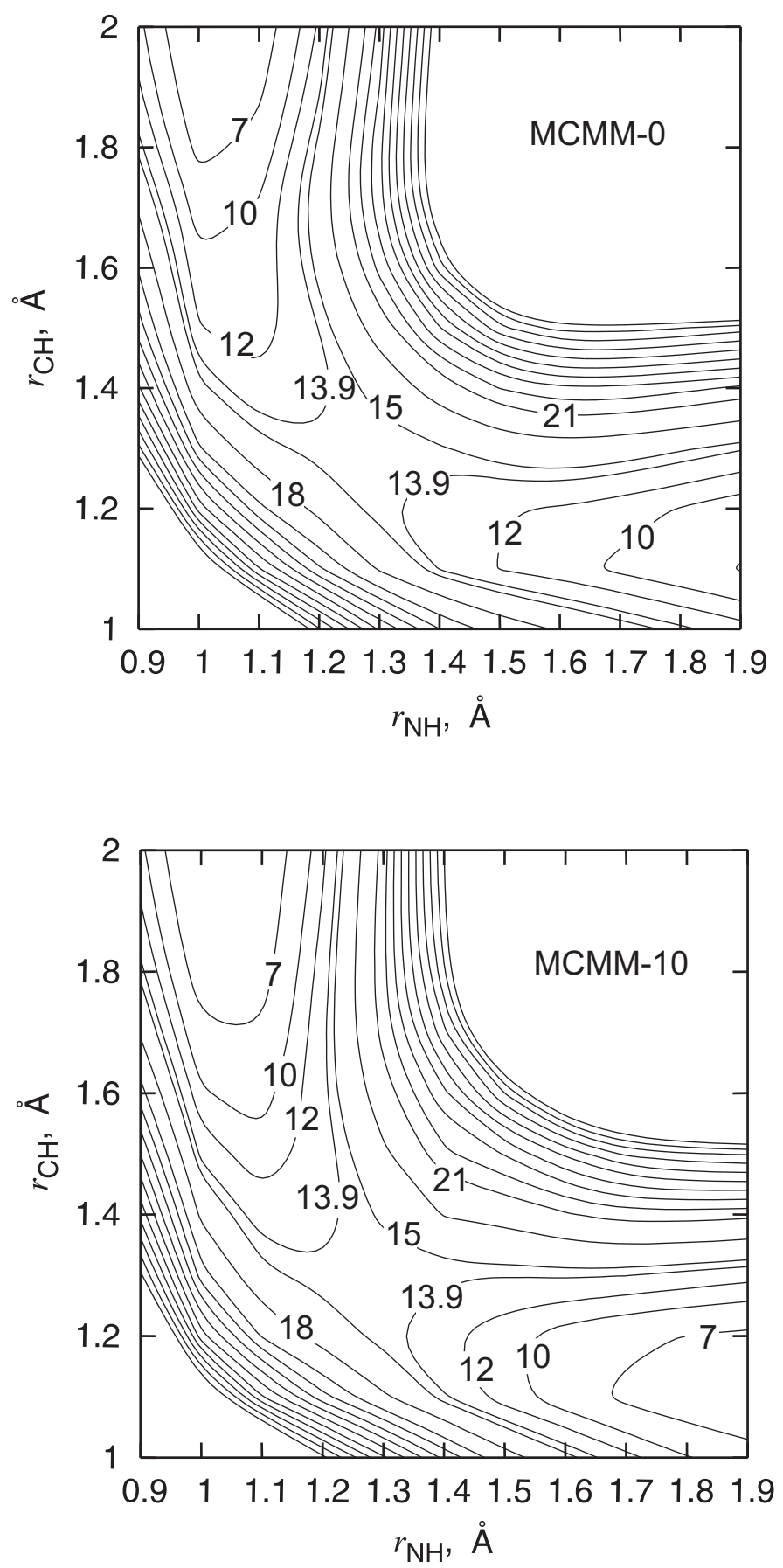